\title{
Thoracolumbar kyphosis in postmenopausal osteoporosis patients without vertebral compression fractures
}

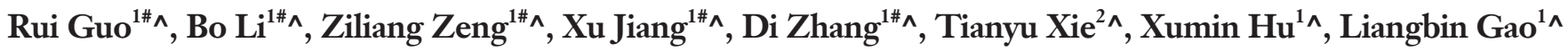 \\ ${ }^{1}$ Department of Spinal Surgery, Sun Yat-sen Memorial Hospital of Sun Yat-sen University, Guangzhou, China; ${ }^{2}$ Sun Yat-sen Memorial Hospital, Sun \\ Yat-sen University, Shenshan Central Hospital, Shanwei, China \\ Contributions: (I) Conception and design: R Guo; (II) Administrative support: X Hu, L Gao; (III) Provision of study materials or patients: B Li; (IV) \\ Collection and assembly of data: Z Zeng, D Zhang; (V) Data analysis and interpretation: T Xie; (VI) Manuscript writing: All authors; (VII) Final \\ approval of manuscript: All authors. \\ \#These authors contributed equally to this work. \\ Correspondence to: Liangbin Gao; Xumin Hu. Department of Spinal Surgery, Sun Yat-sen Memorial Hospital of Sun Yat-sen University, 107 Yanjiang \\ West Road, Guangzhou, China. Email: gaolb@mail.sysu.edu.cn; huxumin3@mail.sysu.edu.cn.
}

Background: To investigate whether thoracolumbar kyphosis (TLK) of the spine is related to the reduction of bone mineral density (BMD) in postmenopausal osteoporosis women, and whether BMD of postmenopausal osteoporosis women can predict the occurrence of TLK.

Methods: This retrospective cohort study included 224 postmenopausal female patients hospitalized for osteoporosis from December 2017 to December 2020, and the control group included 270 postmenopausal female patients hospitalized for thoracolumbar degenerative diseases. The age, body mass index (BMI), visual analogue scale (VAS), and BMD of the lumbar spine $[\mathrm{BMD}(\mathrm{L})]$ and femoral neck $[\mathrm{BMD}(\mathrm{F})]$ of all patients during admission were recorded. We measured and recorded the Cobb angle of thoracolumbar and the height of the thoracolumbar intervertebral space in the spinal X-ray lateral radiograph. The Pearson and Spearman correlation coefficients were used to calculate the correlation between each parameter in the group. The Chi-square test was used for categorical variables, the independent-sample $t$-test was used for normally distributed continuous variables, and two-sample non-parametric tests were used for non-normally distributed variables. Binary logistic regression analysis and receiver operating characteristic (ROC) curves were applied to determine independent risk factors and cut-off values, respectively.

Results: There were significant differences in the $\mathrm{BMD}(\mathrm{L}), \mathrm{BMD}(\mathrm{F})$, thoracolumbar junction Cobb angle, lumbar spine Cobb angle, T11/12-L1/2 height difference of the posterior and anterior edge of intervertebral space (HDPAIS), single vertebra Cobb angle (SVC), procollagen type $1 \mathrm{~N}$-terminal propeptide (PINP) and 25-hydroxyvitamin D [25-(OH)D] between the study and control groups. Through binary logistic regression analysis, we found that BMD(L), PINP, bone alkaline phosphatase, and 25-(OH)D were independent risk factors for future TLK in postmenopausal women. According to the ROC curve, the prediction accuracy of $\mathrm{BMD}(\mathrm{L})$ was the highest. By calculating the critical value, we found that when the $\mathrm{BMD}(\mathrm{L}) \mathrm{T}$-score $<-1.65$, postmenopausal women were more likely to develop TLK.

Conclusions: In postmenopausal osteoporosis patients, TLK will occur even if there is no compression fracture, and when the $\mathrm{BMD}(\mathrm{L}) \mathrm{T}$-score <-1.65, postmenopausal women are more likely to develop TLK in the future.

Keywords: Postmenopausal women; osteoporosis; bone mineral density (BMD); thoracolumbar kyphosis (TLK)

\footnotetext{
^ ORCID: Liangbin Gao, 0000-0002-9333-7336; Xumin Hu, 0000-0002-9330-5502; Tianyu Xie, 0000-0001-6060-201X; Di Zhang, 00000002-1175-7397; Jiang Xu, 0000-0001-5826-5720; Ziliang Zeng, 0000-0002-0095-8396; Bo Li, 0000-0003-0022-0583; Rui Guo, 00000003-1108-6199.
} 
Submitted Nov 02, 2021. Accepted for publication Dec 30, 2021.

doi: $10.21037 / \mathrm{atm}-21-6285$

View this article at: https://dx.doi.org/10.21037/atm-21-6285

\section{Introduction}

Osteoporosis is the most common metabolic bone disease in the elderly, which can lead to bone loss and fragility fractures (1). Postmenopausal women have a higher risk of osteoporosis, with previous reports indicating that about $20 \%$ of postmenopausal women will suffer from osteoporosis (2). Postmenopausal osteoporosis patients have reduced bone mineral density and are prone to serious adverse consequences such as vertebral compression fractures and thoracolumbar kyphosis(TLK) $(3,4)$. TLK can lead to serious physical, emotional, and economic consequences (5-8). Previous studies believed that the thoracolumbar kyphosis was due to compression fracture of the vertebral body (9-12). However, there is little discussion about the presence of thoracolumbar kyphosis in postmenopausal osteoporosis patients without VCF, and the role of bone mineral density in thoracolumbar kyphosis is unclear

Therefore, the purpose of this study is to investigate whether postmenopausal osteoporosis women without VCF suffer from TLK, and whether the bone mineral density (BMD) of postmenopausal osteoporosis women can predict the occurrence of TLK. We present the following article in accordance with the STARD reporting checklist (available at https://atm.amegroups. com/article/view/10.21037/atm-21-6285/rc).

\section{Methods}

\section{Study participants}

This retrospective cohort study collected patient information from our hospital between December 2017 and December 2020. A total of 494 postmenopausal female patients were enrolled. The inclusion criteria were as follows: (I) BMD examination was performed in our hospital from December 2017 to December 2020; and (II) postmenopausal women aged $>55$ years old. The exclusion criteria were as follows: (I) patients with a previous history of osteoporotic VCF and history of spinal surgery (such as spinal fusion surgery, vertebroplasty, or kyphoplasty); (II) patients with congenital spinal deformities and scoliosis; (III) patients with a history of spinal tumors, ankylosing spondylitis, and other spondyloarthritis; and (IV) those with a history of hematological diseases (such as multiple myeloma) or acquired immunodeficiency diseases.

Finally, the patients were divided into study and control groups based on whether osteoporosis without VCF was diagnosed during hospitalization. All procedures performed in this study involving human participants were in accordance with the Declaration of Helsinki (as revised in 2013). The study was approved by Medical Ethics Committee of Sun Yat-sen Memorial Hospital, Sun Yatsen University (No. SYSEC-KY-KS-2021-244) and written informed consent was obtained from all patients.

\section{Diagnostic criteria for osteoporosis and vertebral compression fractures}

A dual-energy X-ray bone densitometer (Lunar DPXIQ, GE, USA) was used to determine the BMD T-score of the lumbar spine and femoral neck. The diagnostic criteria for osteoporosis are based on the criteria established by the World Health Organization (WHO): T-score $>-1.0$ signifies normal bone mass; T-score between -1.0 and -2.5 denotes osteopenia; $T$-score $\leq-2.5$ indicates osteoporosis; fragility fractures (excluding other metabolic bone diseases) are diagnosed as osteoporosis even if the T-score $>2.5$. MRI is used to confirm the diagnosis of vertebral compression fractures. The vertebral compression fractures would be diagnosed when there is a loss of height in the anterior, middle, or posterior dimension of the vertebral body that exceeds $20 \%$.

\section{X-ray imaging measurement}

The imaging parameters were as follows: TLK, lumbar lordosis (LL), TLK + LL, single-segment vertebral Cobb angle (SVC), intervertebral space height (ISH), and the height difference between the posterior and anterior edges of the intervertebral space (HDPAIS) (Figure 1 and Table 1). In this study, a positive Cobb angle was defined as kyphosis, while a negative Cobb angle was defined as lordosis. In all $\mathrm{X}$-ray images, the patients were standing upright, kept their gaze horizontally and their knees straight. All measurements 

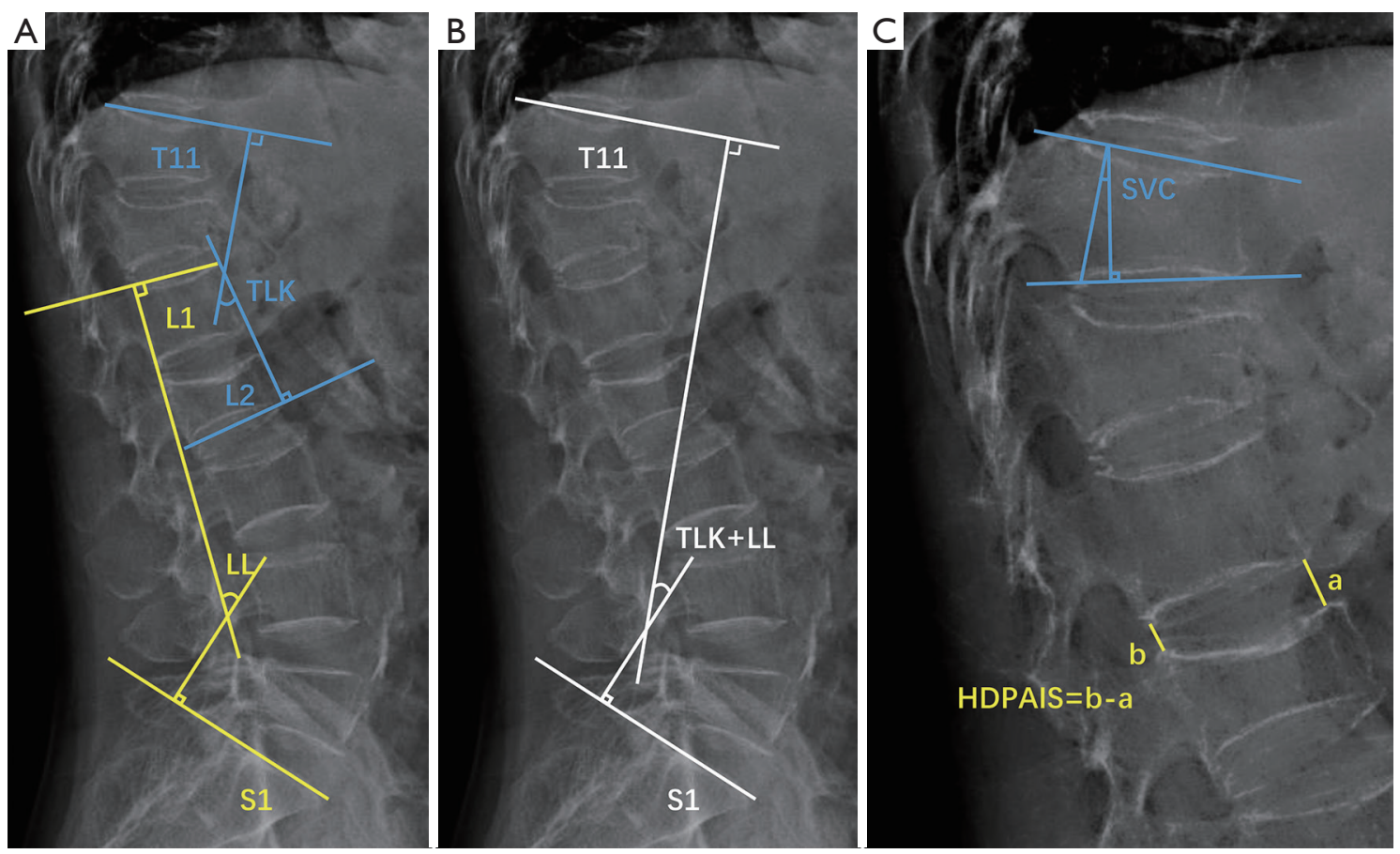

Figure 1 Standard lateral spine radiographs with measurements. (A) TLK and LL. (B) TLK + LL. (C) SVC and HDPAIS. TLK, thoracolumbar kyphosis; LL, lumbar lordosis; TLK + LL, thoracolumbar kyphosis + lumbar lordosis; SVC, single-segment vertebral Cobb angle; HDPAIS, the height difference between the posterior and anterior edges of the intervertebral space.

Table 1 Measurement of sagittal parameters of the spine on X-ray radiographs

\begin{tabular}{ll}
\hline Spine sagittal parameters & Measurement method \\
\hline TLK & Cobb angle between the T11 superior endplate and the L1 inferior endplate (Figure 1A) \\
LL & Cobb angle between the L1 superior endplate and the S1 superior endplate (Figure 1A) \\
TLK + LL & Cobb angle between the T11 superior endplate and the S1 superior endplate (Figure 1B) \\
SVC & Cobb angle between one single-segment vertebral superior endplate and its inferior endplate (Figure 1C) \\
ISH & The vertical distance between the upper and lower endplates at the midpoint of the intervertebral space \\
& (Figure 1C) \\
HDPAIS & The difference in distance between the posterior and anterior edges of the adjacent vertebrae (Figure 1C)
\end{tabular}

TLK, thoracolumbar kyphosis; LL, lumbar lordosis; SVC, single-segment vertebral Cobb angle; ISH, intervertebral space height; HDPAIS, height difference between the posterior and anterior edges of the intervertebral space.

were performed on standard lateral spine radiographs.

\section{Statistical analysis}

SPSS24.0 statistical software (IBM, USA) was used for statistical analysis; continuous variables were expressed as mean \pm standard deviation $(\bar{x} \pm \mathrm{SD})$, and the Pearson correlation coefficient was used to calculate the correlation between the intra-group parameters. The independentsample $t$-test was used for normally distributed continuous variables in the inter-group analysis, while the twosample non-parametric test was used for non-normally distributed variables. Binary logistic regression analysis and receiver operating characteristic (ROC) curve were used to determine independent risk factors and cut-off values, respectively. $\mathrm{P}<0.05$ was considered to indicate statistically 
significant difference.

\section{Results}

\section{Basic data}

In the study group, there were 224 postmenopausal osteoporosis patients without VCF, with an average age of 68 years (55-90 years), body mass index (BMI) of $(23.53 \pm 3.51) \mathrm{kg} / \mathrm{m}^{2}$, and a visual analogue scale (VAS) score of the most painful part in thoracolumbar spine of $2.24 \pm 0.92$. The average $\mathrm{BMD}$ of the lumbar spine $[\mathrm{BMD}(\mathrm{L})]$ T-score was -2.3 , and the average BMD of the femoral neck $[\mathrm{BMD}(\mathrm{F})]$ T-score was -2.3 . The TLK, LL, and TLK + LL were $11.4^{\circ},-42.0^{\circ}$, and $-45.8^{\circ}$, respectively. The average SVC of T11-L2 were $6.0^{\circ}, 5.5^{\circ}, 5.0^{\circ}$, and $4.9^{\circ}$, respectively. The average ISH of T11/T12-L5/S1 were 7.5, 7.9, 9.6, $10.6,11.3,10.7$, and $10.0 \mathrm{~mm}$, respectively. The average HDPAIS of T11/T12-L5/S1 was -3.0, -3.0, -2.8, -5.1, $-6.1,-5.4$, and $-4.3 \mathrm{~mm}$, respectively.

In the control group, there were 270 postmenopausal women without osteoporosis, with an average age of 66 years (55-84 years), BMI of $(24.86 \pm 3.32) \mathrm{kg} / \mathrm{m}^{2}$, and a VAS score of the most painful part in thoracolumbar spine of $1.25 \pm 0.67$. The average $\mathrm{BMD}(\mathrm{L}) \mathrm{T}$-score was -0.8 , and the average $\mathrm{BMD}(\mathrm{F}) \mathrm{T}$-score was -0.8 . The TLK, LL, TLK + LL were $1.34^{\circ},-40.0^{\circ}$, and $-40.6^{\circ}$, respectively. The average SVC of T11-L2 were $4.8^{\circ}, 2.7^{\circ}, 3.3^{\circ}$, and $4.0^{\circ}$, respectively. The average ISH of T11/T12-L5/S1 were $7.1,8.0,9.1,10.2,10.1,9.0$, and $8.7 \mathrm{~mm}$, respectively. The average HDPAIS of T11/T12-L5/S1 was $-1.2,-2.0,-3.1$, $-4.4,-3.3,-2.8$, and $-2.5 \mathrm{~mm}$, respectively. The details are described in Table 2.

The Shapiro-Wilk normal test was used for continuous variables. We found that age, BMI, serum calcium, serum phosphorus, TLK, LL, and TLK + LL showed a normal distribution. The VAS score, $\mathrm{BMD}(\mathrm{L}), \mathrm{BMD}(\mathrm{F})$, SVC, HDPAIS, b_Crosslaps, $\mathrm{N}$-terminal midfragment of osteocalcin (N_MID), procollagen type $1 \mathrm{~N}$-terminal propeptide (PINP), bone alkaline phosphatase, and 25-hydroxyvitamin D [25-(OH)D] were all non-normally distributed.

\section{Comparison between the study and control groups}

For categorical variables, the chi-square test was used for inter-group analysis. As for continuous variables, the independent-sample $t$-test was used for normally distributed; otherwise, the two-sample non-parametric test was used. We found that there were significant differences in $\operatorname{BMD}(\mathrm{L}), \mathrm{BMD}(\mathrm{F})$, TLK, LL, T11/12-L1/2 HDPAIS, and T11-L2 SVC between the study and control groups (Figure 2). There were no significant differences in sex, TLK + LL, serum calcium, serum phosphorus, serum iron, b_Crosslaps, or N_MID. These results indicated that the osteoporosis group had a lower BMD, higher TLK and LL, and a larger T11/12-L1/2 HDPAIS.

\section{Binary logistic regression analysis and ROC curve analysis were used to determine the independent risk factors}

Through binary logistic regression analysis, we found that BMD(L), BMD(F), T11/T12 HDPAIS, L1/L2 HDPAIS, PINP, and 25-(OH)D were independent risk factor for future TLK in postmenopausal women. The details are described in Table 3.

In order to further evaluate the degree of influence of each risk factor, the ROC curve was used for comparison and judgment. According to the ROC curve, the prediction accuracy of $\mathrm{BMD}(\mathrm{L})$ was the highest (the area under the curve was 0.848) (Figure 3 and Table 4). By calculating the critical value, we found that when the $\mathrm{BMD}(\mathrm{L}) \mathrm{T}$-score $<-1.65$, postmenopausal women were more likely to develop TLK in the future $(\mathrm{P}<0.001, \mathrm{OR}=0.665)$.

\section{Intragroup analysis results of the study and control groups}

The Pearson correlation coefficient was used to calculate the correlation between various parameters. In the study group, age was negatively correlated with BMD and positively correlated with TLK.

The above results indicated that in the osteoporotic group, older age was associated with worse BMD; the older the age, the worse the BMD and the greater the Cobb angle of the thoracolumbar junction, and thus, the more severe the TLK will be in the future. This finding further emphasized the importance of BMD in the prediction of TLK in postmenopausal women in the future. The details are described in Table 5.

In the control group, age was negatively correlated with BMD. BMD(F) was positively correlated with bone alkaline phosphatase. The above results indicated that in postmenopausal non-osteoporotic women, the older the age, the worse the BMD. In addition, decreased 
Table 2 Comparison of the basic information between study and control groups

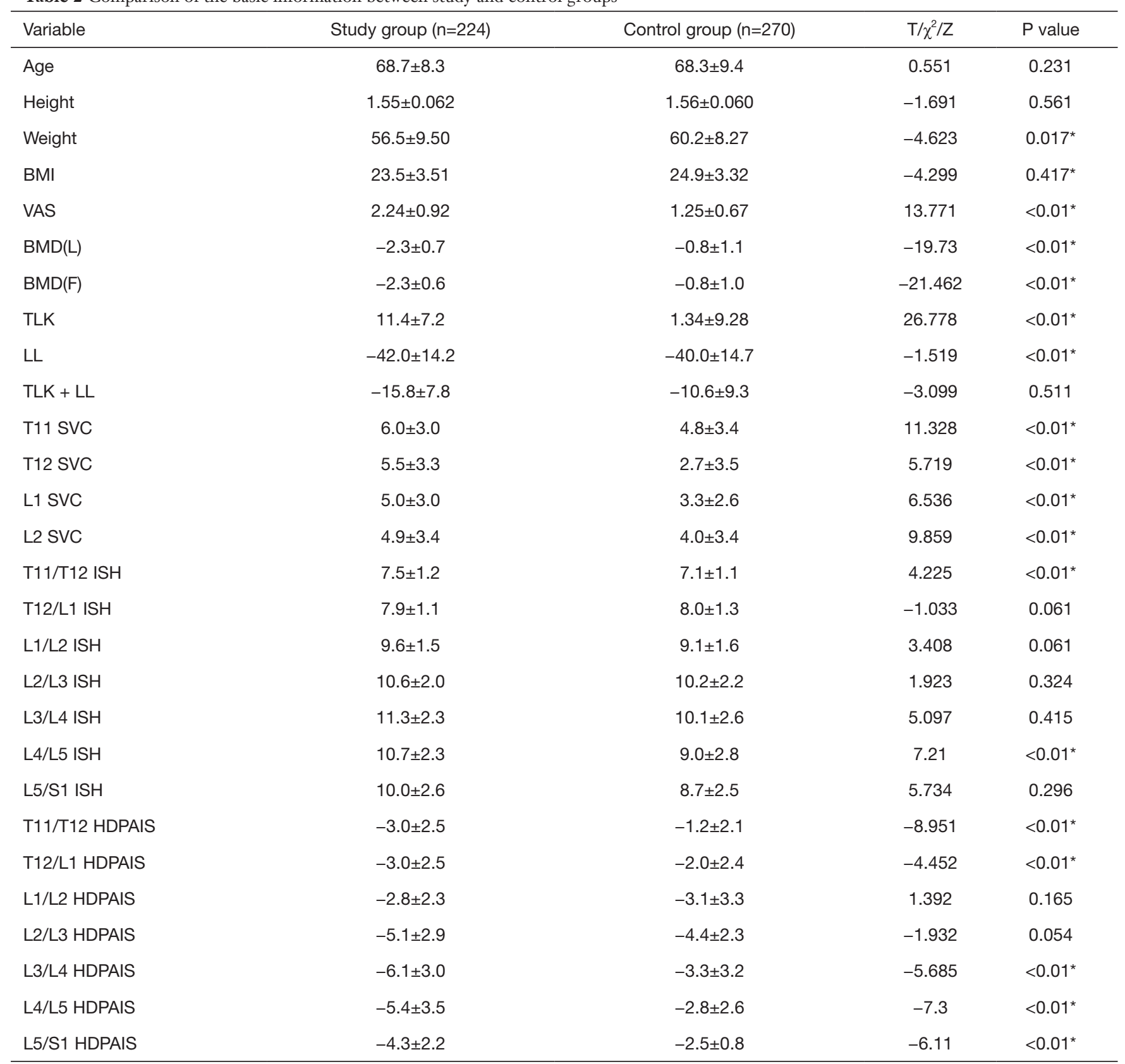

*, P<0.05. BMI, body mass index; VAS, visual analogue scale; BMD, bone mineral density; TLK, thoracolumbar kyphosis; LL, lumbar lordosis; SVC, single-segment vertebral Cobb angle; ISH, intervertebral space height; HDPAIS, the height difference between the posterior and anterior edges of the intervertebral space.

bone alkaline phosphatase was associated with decreased $\mathrm{BMD}$, which highlights that it may be possible to predict the changes in BMD using the decrease of bone alkaline phosphatase, so as to determine the possibility of TLK in the future. The details are described in Table 6 .

\section{Discussion}

This study describes the changes in the thoracolumbar sagittal sequence of postmenopausal osteoporosis patients without VCF. The results showed that the BMD of the 

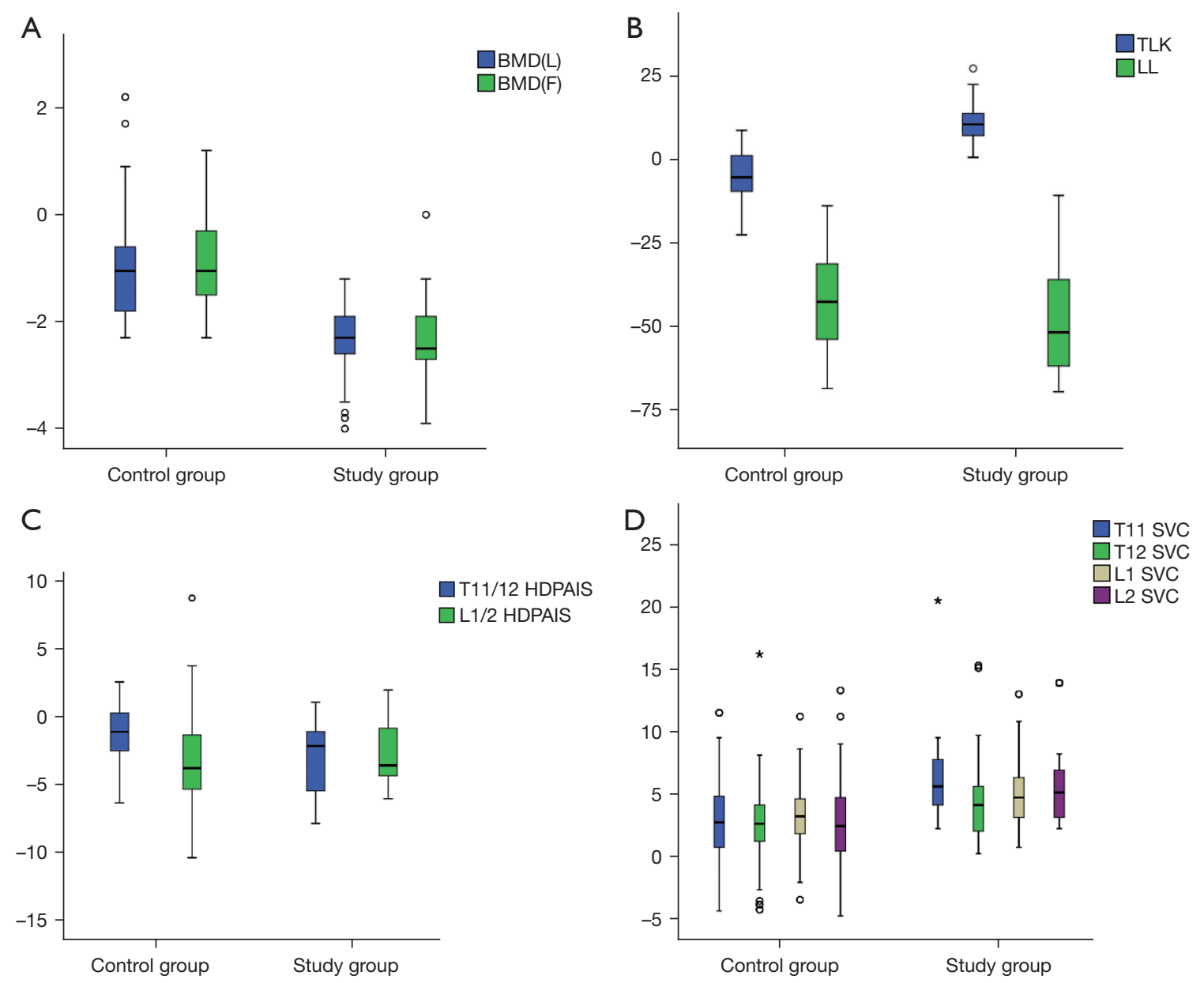

Figure 2 Significant parameter differences between the study group and the control group. (A) BMD(L) and BMD(F) differences between the study and control groups. (B) TLK and LL differences between the two groups. (C) T11/12 and L1/2 HDPAIS differences between the two groups. (D) T11-L2 SVC difference between the two groups. *, outliers in the data. BMD, bone mineral density; TLK, thoracolumbar kyphosis; LL, lumbar lordosi; HDPAIS, the height difference between the posterior and anterior edges of the intervertebral space; SVC, single-segment vertebral Cobb angle.

Table 3 Binary logistic regression analysis to determine independent risk factors

\begin{tabular}{|c|c|c|c|c|c|}
\hline \multirow{2}{*}{ Variable } & \multirow{2}{*}{$\mathrm{B}$} & \multirow{2}{*}{$P$ value } & \multirow{2}{*}{ OR } & \multicolumn{2}{|c|}{$95 \%$ confidence interval of OR } \\
\hline & & & & Lower bound & Upper bound \\
\hline $\mathrm{BMD}(\mathrm{L})$ & -0.408 & $<0.001^{*}$ & 0.665 & 0.436 & 1.015 \\
\hline T11/T12 HDPAIS & -0.354 & $0.008^{\star}$ & 0.702 & 0.587 & 0.839 \\
\hline L1/L2 HDPAIS & 0.222 & $0.020^{\star}$ & 1.249 & 1.102 & 1.416 \\
\hline PINP & 0.037 & $0.043^{*}$ & 1.037 & 1.013 & 1.062 \\
\hline Bone alkaline phosphatase & -0.038 & 0.239 & 0.963 & 0.940 & 0.986 \\
\hline $25-(\mathrm{OH}) \mathrm{D}$ & 0.030 & $0.049^{*}$ & 1.030 & 1.012 & 1.049 \\
\hline
\end{tabular}

*, $\mathrm{P}<0.05$. BMD, bone mineral density; HDPAIS, the height difference between the posterior and anterior edges of the intervertebral space; SVC, single-segment vertebral Cobb angle; PINP: procollagen type $1 \mathrm{~N}$-terminal propeptide OR, odds ratio. 


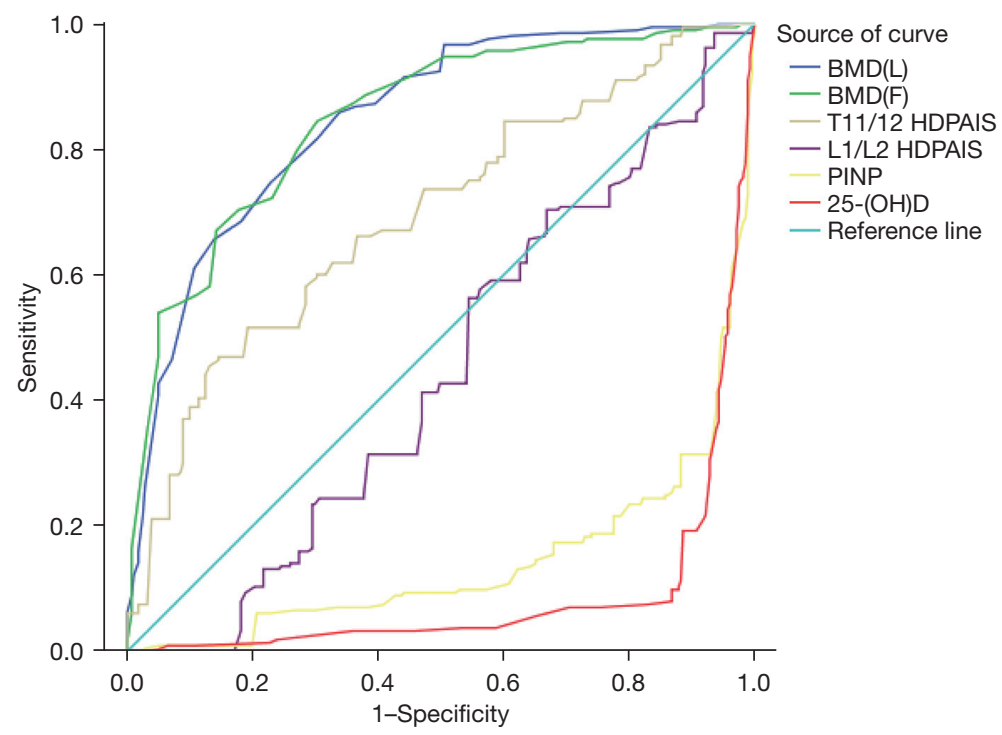

Figure 3 ROC curve of $\mathrm{BMD}(\mathrm{L})$, BMD(F), T11/12 HDPAIS, L1/L2 HDPAIS, PINP, and 25-(OH)D. ROC, receiver operating characteristic; BMD, bone mineral density; HDPAIS, the height difference between the posterior and anterior edges of the intervertebral space; PINP: procollagen type $1 \mathrm{~N}$-terminal propeptide.

Table 4 Area under the curve

\begin{tabular}{|c|c|c|c|c|c|}
\hline Parameter & Area & Standard deviation & $P$ value & \multicolumn{2}{|c|}{$95 \%$ confidence interval } \\
\hline $\mathrm{BMD}(\mathrm{L})$ & 0.848 & 0.017 & $<0.001$ & 0.815 & 0.882 \\
\hline $\mathrm{BMD}(\mathrm{F})$ & 0.847 & 0.017 & $<0.001$ & 0.815 & 0.883 \\
\hline T11/T12 HDPAIS & 0.693 & 0.024 & $<0.001$ & 0.646 & 0.741 \\
\hline PINP & 0.144 & 0.018 & $<0.001$ & 0.109 & 0.180 \\
\hline $25-(\mathrm{OH}) \mathrm{D}$ & 0.086 & 0.014 & $<0.001$ & 0.058 & 0.113 \\
\hline
\end{tabular}

BMD, bone mineral density; HDPAIS, the height difference between the posterior and anterior edges of the intervertebral space; PINP: procollagen type $1 \mathrm{~N}$-terminal propeptide.

osteoporosis group was generally lower than that of the non-osteoporosis group, and the difference between the two groups was statistically significant $(\mathrm{P}<0.01)$. The possible reason is that the lack of estrogen leads to bone loss and changes in bone tissue structure. Furthermore, the TLK of the osteoporosis group was generally larger than that of the non-osteoporosis group, and the difference between the two groups was statistically significant $(\mathrm{P}<0.01)$. We also found that even if there was no VCF, postmenopausal osteoporosis patients will still suffer from mild wedge-shaped deformations of the thoracolumbar junction (T11-L2 SVC was $\left.4.9^{\circ}-6^{\circ}\right)$. The reason for this is that the low BMD and microstructural changes associated with osteoporosis might reduce the biomechanical strength of the vertebral body, especially in the anterior column (13). Longitudinal stress load destroys the endplate and trabecular bone of the vertebral body, leading to progressive collapse of the anterior cortex and a wedge-shaped deformation of the vertebral body (14). The thoracolumbar junction is the stress concentration area of the entire spine, so wedgeshaped deformations of the vertebral body are most obvious in the thoracolumbar spine (15). The TLK may be more 


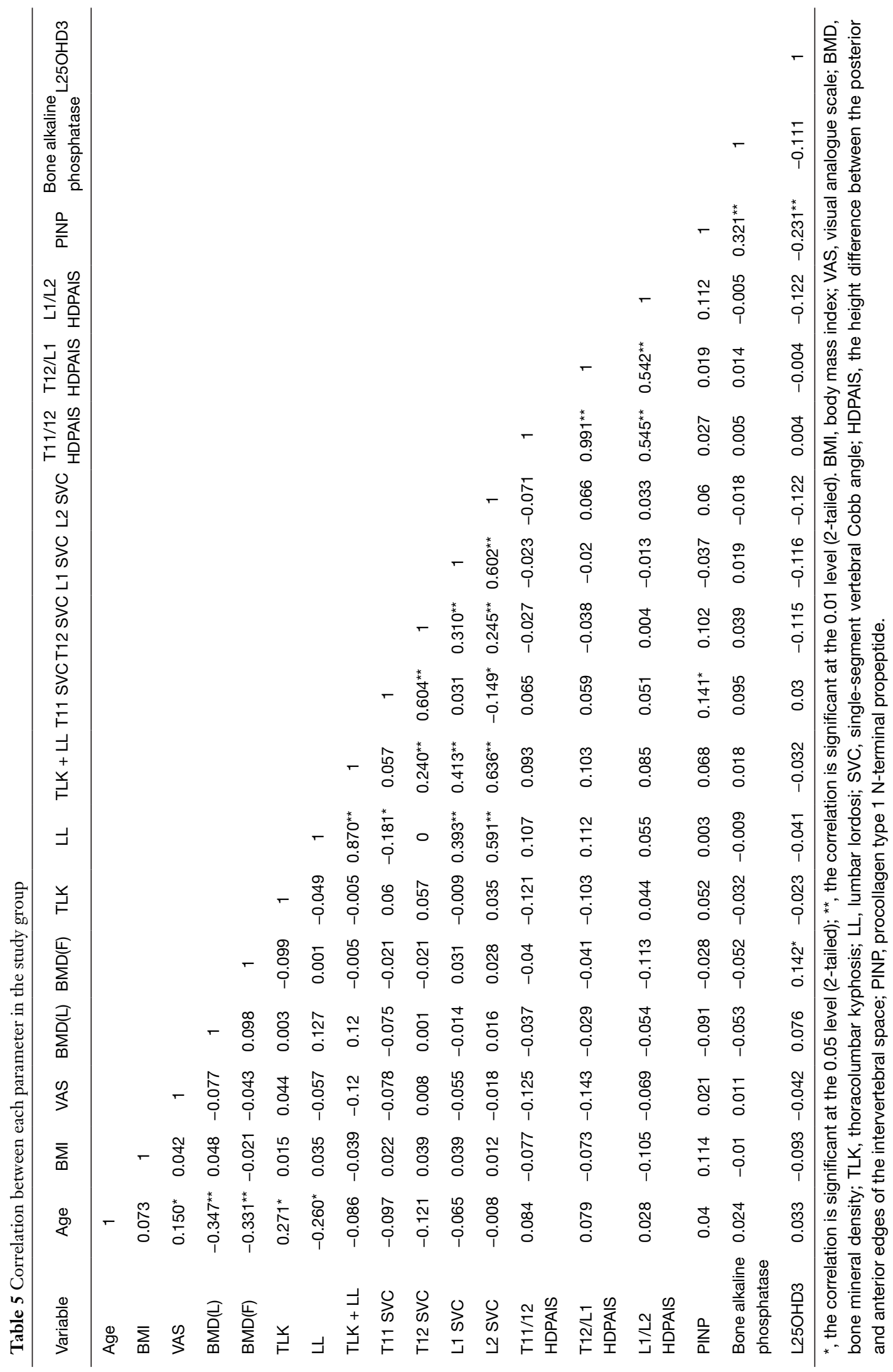




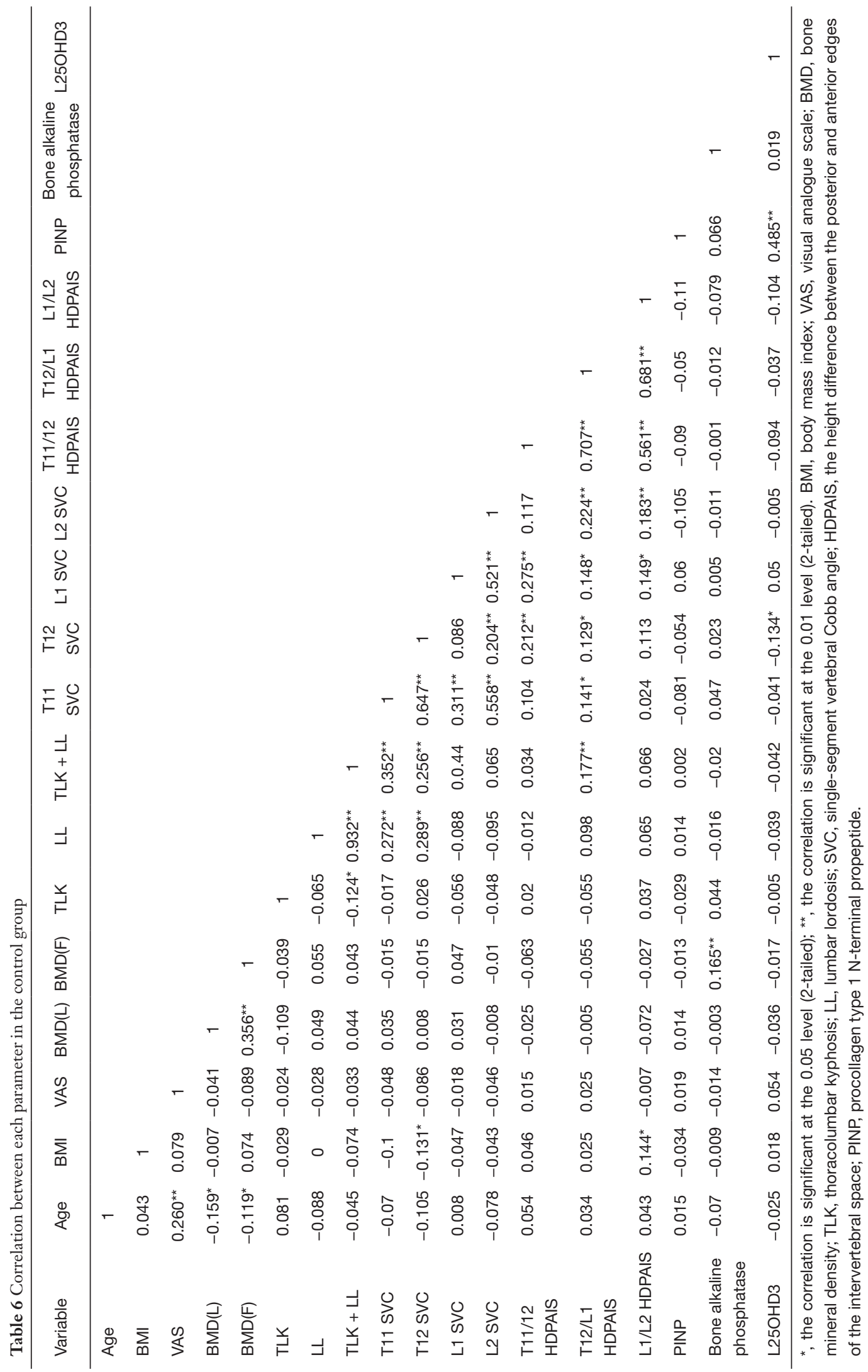


important to the biomechanical environment of the spine than the thoracic kyphosis, because it produces a longer moment arm $(16,17)$. Consistently, Lee et al. (18) found that there were significant differences in the parameters of the spine-pelvic sagittal plane between patients with osteoporosis and those without osteoporosis.

We also found that $\mathrm{BMD}(\mathrm{L})$ is the most important independent risk factor for TLK in postmenopausal women. When the BMD(L) T-score $<-1.65$, postmenopausal women were more likely to develop TLK in the future. We think this is because the $\mathrm{BMD}(\mathrm{L})$ represents the $\mathrm{BMD}$ of the entire spine vertebral body. Decreased BMD of the vertebral body indicates that the bone strength of the vertebral body is decreased, and the compressive strength of the vertebral body is weakened, resulting in compression of the anterior part of the vertebral body, and finally the occurrence of TLK.

Numerous researchers believe that TLK without VCF will not cause serious consequences $(19,20)$. However, our study found that compared with the control group, the osteoporosis group had more severe TLK and higher VAS scores at admission, and the difference was statistically significant. This shows that the degree of TLK affects the patient's pain perception. When the wedge-shaped deformation of the vertebral body becomes severe, not only will the TLK appear, but the overall sagittal plane of the spine will also be damaged, causing the center of gravity to move forward. This will increase the continuous tension of the back muscles, leading to chronic back pain. If decompensation occurs as the disease progresses, the spine becomes more prone to fractures, resulting in serious consequences (21). For these patients, we recommend strengthening the back muscles to restore the sagittal balance of the thoracolumbar spine. If the kyphosis is severe, crutches or even surgical correction are required to reduce the risk of accidental falls and fractures

There are some limitations in this study that should be considered. Firstly, since this is a retrospective study, all patient data came from a single center, and our results cannot establish any causal relationship. We cannot confirm the chronological sequence of BMD reduction and TLK. Follow-up prospective cohort studies can be used to clarify the relationship between the decrease in BMD and TLK in postmenopausal women.

\section{Conclusions}

For postmenopausal women, TLK will occur even if there is no VCF, and when the $\mathrm{BMD}(\mathrm{L}) \mathrm{T}$-score $<-1.65$, postmenopausal women are more likely to develop TLK in the future. Since TLK increases the risk of VCF, it is better to correct the TLK before the fracture occurs instead of treating the patient after the fracture, so as to prevent the fracture. This will have a more positive effect on the life and health of patients

\section{Acknowledgments}

Funding: This study was supported by the Science and Technology Program of Guangzhou, China (201707010089); Medical Science and Technology Research Foundation of Guangdong Province, Guangzhou, China (A2021371); Basics and Application Basics of Guangzhou (202102020096); and Regenerative Medicine and Health Laboratory of Guangzhou, Guangdong (1102101201).

\section{Footnote}

Reporting Checklist: The authors have completed the STARD reporting checklist. Available at https://atm.amegroups. com/article/view/10.21037/atm-21-6285/rc

Data Sharing Statement: Available at https://atm.amegroups. com/article/view/10.21037/atm-21-6285/dss

Conflicts of Interest: All authors have completed the ICMJE uniform disclosure form (available at https://atm. amegroups.com/article/view/10.21037/atm-21-6285/coif). The authors have no conflicts of interest to declare.

Ethical Statement: The authors are accountable for all aspects of the work in ensuring that questions related to the accuracy or integrity of any part of the work are appropriately investigated and resolved. The study was approved by Medical Ethics Committee of Sun Yat-sen Memorial Hospital, Sun Yat-sen University (No. SYSECKY-KS-2021-244) and written informed consent was obtained from all patients. All procedures performed in this study involving human participants were in accordance with the Declaration of Helsinki (as revised in 2013).

Open Access Statement: This is an Open Access article distributed in accordance with the Creative Commons Attribution-NonCommercial-NoDerivs 4.0 International License (CC BY-NC-ND 4.0), which permits the noncommercial replication and distribution of the article with the strict proviso that no changes or edits are made and the 
original work is properly cited (including links to both the formal publication through the relevant DOI and the license). See: https://creativecommons.org/licenses/by-nc-nd/4.0/.

\section{References}

1. Cosman F, de Beur SJ, LeBoff MS, et al. Clinician's Guide to Prevention and Treatment of Osteoporosis. Osteoporos Int 2014;25:2359-81.

2. Lix LM, Azimaee M, Osman BA, et al. Osteoporosisrelated fracture case definitions for population-based administrative data. BMC Public Health 2012;12:301.

3. Marcus R, Drinkwater B, Dalsky G, et al. Osteoporosis and exercise in women. Med Sci Sports Exerc 1992;24:S301-7.

4. Melton LJ 3rd, Kan SH, Frye MA, et al. Epidemiology of vertebral fractures in women. Am J Epidemiol 1989;129:1000-11.

5. Hoyt D, Urits I, Orhurhu V, et al. Current Concepts in the Management of Vertebral Compression Fractures. Curr Pain Headache Rep 2020;24:16.

6. Marchenkova LA, Makarova EV. Exercise therapy and bracing in patients with osteoporotic compression vertebral fractures. Vopr Kurortol Fizioter Lech Fiz Kult 2019;96:69-75.

7. Imagama $\mathrm{S}$, Hasegawa $\mathrm{Y}$, Matsuyama $\mathrm{Y}$, et al. Influence of sagittal balance and physical ability associated with exercise on quality of life in middle-aged and elderly people. Arch Osteoporos 2011;6:13-20.

8. Wright NC, Looker AC, Saag KG, et al. The recent prevalence of osteoporosis and low bone mass in the United States based on BMD at the femoral neck or lumbar spine. J Bone Miner Res 2014;29:2520-6.

9. Cho Y, Lee G, Aguinaldo J, et al. Correlates of bone mineral density and sagittal spinal balance in the aged. Ann Rehabil Med 2015;39:100-7.

10. Burger H, Van Daele PL, Grashuis K, et al. Vertebral deformities and functional impairment in men and women. J Bone Miner Res 1997;12:152-7.

11. Pluijm SM, Tromp AM, Smit JH, et al. Consequences of

Cite this article as: Guo R, Li B, Zeng Z, Jiang X, Zhang D, Xie T, Hu X, Gao L. Thoracolumbar kyphosis in postmenopausal osteoporosis patients without vertebral compression fractures. Ann Transl Med 2022;10(2):52. doi: 10.21037/atm-21-6285 vertebral deformities in older men and women. J Bone Miner Res 2000;15:1564-72.

12. Nevitt MC, Ettinger B, Black DM, et al. The association of radiographically detected vertebral fractures with back pain and function: a prospective study. Ann Intern Med 1998;128:793-800.

13. Hou Y, Luo Z. A study on the structural properties of the lumbar endplate: histological structure, the effect of bone density, and spinal level. Spine (Phila Pa 1976) 2009;34:E427-33.

14. Landham PR, Gilbert SJ, Baker-Rand HL, et al. Pathogenesis of Vertebral Anterior Wedge Deformity: A 2-Stage Process? Spine (Phila Pa 1976) 2015;40:902-8.

15. Hempfing A, Zenner J, Ferraris L, et al. Restoration of sagittal balance in treatment of thoracic and lumbar vertebral fractures. Der Orthopade 2011;40:690-702.

16. Ailon T, Shaffrey CI, Lenke LG, et al. Progressive Spinal Kyphosis in the Aging Population. Neurosurgery 2015;77 Suppl 4:S164-72.

17. Grigoryan M, Guermazi A, Roemer FW, et al. Recognizing and reporting osteoporotic vertebral fractures. Eur Spine J 2003;12 Suppl 2:S104-12.

18. Lee JS, Lee HS, Shin JK, et al. Prediction of sagittal balance in patients with osteoporosis using spinopelvic parameters. Eur Spine J 2013;22:1053-8.

19. Boseker EH, Moe JH, Winter RB, et al. Determination of "normal" thoracic kyphosis: a roentgenographic study of 121 "normal" children. J Pediatr Orthop 2000;20:796-8.

20. Kasukawa Y, Miyakoshi N, Hongo M, et al. Age-related changes in muscle strength and spinal kyphosis angles in an elderly Japanese population. Clin Interv Aging 2017;12:413-20.

21. Baek SW, Kim C, Chang H. The relationship between the spinopelvic balance and the incidence of adjacent vertebral fractures following percutaneous vertebroplasty. Osteoporos Int 2015;26:1507-13.

(English Language Editor: A. Kassem) 